\title{
Progress in indicators to assess agricultural landscape valuation: how and what is measured at different levels of governance
}

\author{
M.L. Paracchini . T.Pinto Correia . I. Loupa-Ramos . C. Capitani . L. Madeira
}

Keywords: Rural landscape; Composite indicator; Societal valuation; Public good; Policy assessment

\begin{abstract}
:
Landscape is defined by the European Landscape Convention as "an area perceived by people, whose character is the result of the action and interaction of natural and/or human factors". Many efforts have been devoted in addressing the core concepts on which this definition roots: perception and interaction of men and nature, but when coming to large (continental) scale assessments, the latter prevail on the former.

This paper aims at presenting a framework for a measurable landscape awareness indicator as a key link to the public demand for a specific type of landscape: the agricultural landscape. This is a necessary effort to complement more physically based assessments, which include as well the impact of human activities on landscapes.

The analysis is carried out at different levels of governance: EU and regional, using an example from the Alentejo region in Portugal and EU wide databases, and addresses conceptual and practical questions: what type of societal landscape awareness can be monitored and by whom (e.g., individuals, specific social groups, society as a whole); what are the landscape dimensions that should be assessed; what are the limitations imposed by data-related constraints. By applying the methodology to build composite indicators to map landscape societal awareness, the paper shows the regional and local meaning of indicator approaches developed at European level, presents developments for downscaling to regional level, while introducing the social component to support sound policy development for European rural landscapes.
\end{abstract}

